\title{
An Economic-environmental-energy Efficiency Analysis for Optimizing Organic Waste Treatment of a Livestock-orchard System: A Case in the Mekong Delta, Vietnam
}

\section{Nguyen Thi Thu Thao}

Ho Chi Minh City University of Technology and Education

Tran Thi Hieu

IER, VNU-HCM

Nguyen Thi Phuong Thao

IER, VNU-HCM

Le Quoc Vi

IER, VNU-HCM

Hans Schnitzer

TU Graz: Technische Universitat Graz

Son Le Thanh

HCMUNRE: Truong Dai hoc Tai nguyen va Moi truong Thanh pho Ho Chi Minh

\section{Gerhart Braunegg}

ARENA research, GRAZ

Sibylle Braunegg

Stadtlabor, Graz, Austria

Hai Thanh Le ( $\nabla$ haile3367@yahoo.com )

Institute for Environment and Resources, Vietnam National University, HoChiMinh City https://orcid.org/0000-0002-7748-8281

Original article

Keywords: Biochar, Biofuel, Biomass Pellet, Integrated Livestock-Orchard System, Mekong Delta

Posted Date: September 20th, 2021

DOl: https://doi.org/10.21203/rs.3.rs-885740/v1

License: (9) (1) This work is licensed under a Creative Commons Attribution 4.0 International License.

Read Full License 


\section{Abstract}

\section{Background}

Economic benefit has been analyzed for the yield of farming products when designing a farming system, while waste treatment also generates profitable energy products for this system. The economic factor is decisive in decision-making for applying waste treatment solutions for a small-scale farming system. A household farming system in the Mekong Delta generates many kinds of organic wastes, but most of the agricultural waste resources are disposed of into the environment.

\section{Methods}

This study approaches an analysis of economic-environmental-energy (EEE) efficiency for waste treatment of an integrated livestock-orchard (LO) system on a household scale in the Mekong Delta. This novel analysis method is based on the energy content of biomass and its cost. The EEE efficiency is optimized to gain objective functions regarding energy yield efficiency, system profit, and $\mathrm{CO}_{2}$ sequestration for the treatment model. The algorithms are built for optimizing these objective functions.

\section{Results}

The optimization results show the treatment model of pyrolysis and pelleting gain all the objective functions with high efficiency. The model is efficiently applied for the LO system that generates more than 100 kilograms of orchard residues and 3,000 kilograms of pig manure. The system with a charcoal oven and pellet machine is capable to gain energy efficiency due to its potential biofuel products, such as biochars and pellet products. A treatment model of composting, pyrolysis, and pelleting gives the best performance of overall EEE efficiency.

\section{Conclusions}

This work has proven economic benefits from integrating biogas tank, charcoal oven, and pellet machine in an integrated LO system. The system contributes not only for reducing $\mathrm{CO}_{2}$ emissions but also for supplementing secondary renewable bioenergy, as well as for increasing incomes and thus supporting livelihoods for the local farming households.

\section{Introduction}

The agricultural sector generates various kinds of biological wastes that have great potential for recycling into useful secondary products as fertilizers or biofuels [1, 2]. Biofuel products from waste have been recognized as an environmentally friendly alternative to coal and fossil fuels [3]. Compared with the characteristics of raw biowaste, biofuel has high bulk density, low moisture content, and high energy content [4]. In addition, they are $\mathrm{CO}_{2}$-neutral and commercially valuable fuels, easy to transport and store $[5,6]$. The potential of energy biomass has encouraged research on converting biomass to biofuel products. Besides, the market value of biofuel also attracts attention to decision-making in investing the 
consistent treatment facilities [7]. The work of Jing (2021) [8] considers economic and environmental trade-offs that link multi-energy obtained from treating organic wastes and rooftop farming. The author remarked that the market price of the secondary energy products affects the profit for an eco-industrial energy system; economic benefits are the main factor to consider treatment technology for the system.

Analyzing economic benefits is applied for agricultural systems in rural [9-12] and in urban $[8,13,14]$. These studies focus on economic and environmental efficiency in resource use to design farming systems. Whereas, the studies of Raviv et al. (2018) [7] and Song et al. (2021) [15] are interested in the profits obtained from the waste treatment system. Raviv et al. (2018) [7] focuses on profitability analysis for the treatment model of agricultural residues (leaf, wood, and vegetable) to generate energy products. Song et al. (2021) [15] evaluates the economic benefits from the anaerobic digestion of animal, plant residues, and biochar to produce biogas and biochar. Thus, not only raw biomass (plant residues) but also intermediate products after treatment (compost and anaerobic digestate) have the potential for energy production $[16,17]$. The study of Vadenbo et al. (2018) [18] demonstrates the environmental benefits of fecal energy, while also highlights the constraints of technology and economy on the energy potentials of biomass.

Ordinarily, treatment solutions of organic waste are represented by composting and anaerobic digesting that produce products with low energy content. Pyrolysis and pelleting are popular thermochemical processes for generating biofuels [19-21]. Pyrolysis decomposes organic materials under non-oxidizing conditions and creates fuels with much energy content [5, 20,22, 23]. Gas, bio-oil, and biochar are energy products of pyrolysis that can be used to produce energy [19]. In addition, pelleting is another technique of thermochemical conversion. Raw materials for biochar and pellet products are diverse such as rice husks, wood chips, straws, etc. [5, 24,25], and from secondary products after treatment such as biogas sludge [26] and compost [27]. They are similar to waste sources arising from the livestock-orchard system, so our research prioritizes applying the above two treatment solutions to this system. Besides, the market price of biochar and biomass pellets is many times higher than that of compost $[7,28]$. Among biofuels, biomass pellets present many advantages in the great market by the abundant materials with relatively simple processing techniques [5]. Despite the uncertainty of demand and market prices for our case study area and parts of the world, these biofuels would be the primary sources of renewable energy in the context of local perspectives where people have only seen the role of compost.

An agricultural system with many production components, also known as an integrated farming system [29] such as a livestock-crop system, generates diverse kinds of waste that need multiple treatment solutions [30]. The studies of Hai et al. [31,32] proposed many solutions for treating wastes from this system, including biogas digester, composting, pyrolysis. The system reaches a zero-emission goal yet overlooks the economic profitability of waste-based energy products. To the best of our knowledge, there is a lack of studies on the energy and economic efficiency of treating organic waste to create energy products for an integrated agricultural system in rural Vietnam. The economic factor is one of the most significant bases to estimate the performance efficiency of a waste treatment system. A small-scale farming household system necessarily takes it into account, especially with the system in the poor 
countryside areas such as the acidic-soil areas in the Mekong Delta, where most of the agricultural waste resources are disposed directly into the environment [30]. The lack of research literature calls for further research on the profitability of waste treatment solutions to produce energy in a farming system.

This study aims to build a new approach to the optimal model for waste treatment in terms of EEE efficiency to fulfill the shortcomings of earlier studies. On the point of view of economic benefits, profit determines investment opportunities for a system, which leads this work to focus on waste treatment solutions to create waste-to-energy products for an orchard-livestock (LO) system of a farming household on a small-scale level. In this system, organic wastes derived from the orchard and pigsty are used for pyrolysis and pelleting to produce biofuels. Then, input-output data of material and energy flows engaged in each treatment solution are analyzed; thereby, the efficiency of treatment solutions related to energy, profit, and environment is evaluated via multi-objective algorithms.

This study considers some experiments in the field of waste treatment facilities to simulate scenarios for treatment systems, and then applies economic analysis and analysis of material and energy flows that enter these systems. Analysis methods are developed from the work of Chen et al. (2019) and Munster et al. $(2015)[33,34]$ to optimize the efficiency of treatment systems. Chen et al. (2019) [33] introduces an integrated treatment technology for municipal solid waste and sludge in terms of energy, economic and environmental impacts through methods of life cycle assessment, and techno-economic, and energy analysis. Energy analysis is applied for the energy use of fossil fuels and renewable energy in treatment models [33]. Economic analysis is used for evaluating the economic and social benefits of incineration plants in terms of initial investment, operating costs, and revenue. Munster et al. (2015) [34] employed a combined method of new cost optimization and a life cycle assessment to optimize costs or greenhouse gas emissions for the domestic waste treatment model. Alternatives for domestic waste treatment include incineration or biogas digester for heat and power generation [34]. The author also highlights the need to integrate waste and energy systems into the waste treatment model.

Generally, our study will design waste treatment systems for LO systems to optimize their performance efficiency regarding energy yield, profit, and $\mathrm{CO}_{2}$ reduction. Since the characteristics of a specific system affect the objectives of optimization assumptions for the treatment model [34], different optimization assumptions for the treatment model of the LO system are related to the production of energy products. Algorithms use the parameters based on data of the model to apply for the objective functions of performance efficiency. Economic analysis is developed from the formulas of Chen et al. (2019) [33], which comparing the market price of energy products and their estimated price. The estimated price is calculated by dividing the investment and operating cost by the number of products from the treatment equipment. Energy efficiency is evaluated by the formula of Munster et al. (2015) [34] regarding the energy content of inputs and outputs. Finally, mathematical optimization of EEE efficiency is developed for the treatment model of the LO system.

\section{Materials And Methods}




\section{Case study description}

The typical demographic structure of a farming household within an acidic soil area of the Mekong Delta is, on average, from 3 to 4 members or more from 2 generations, or from 5 people or more from 3 generations living together in one household, and there are always at least 2 working laborers in each family. Within a typical farming household there are main components such as homestead and fruit trees orchard, pond, and paddy field/crop field, where the homestead normally includes also the livestock shed. The productive components of a rural farming household in this acidic soil areas are combined types of four components: House-Orchard-Livestock-Pond. Ponds are mainly in the forms of ditches and irrigation canals that cannot be used for aquaculture purpose because the water is contaminated with acidic components ( $\mathrm{pH}$ level is lower than 5.0). Livestocks are commonly raised in a form of sheds in a local household. The land use for a farming household is commonly above $500 \mathrm{~m}^{2}$, in which orchard land can only grow some kinds of fruit trees such as mango, banana etc which are suitable for the acidic soil area under study in Mekong delta [35]. In brief, in the agricultural system of a household there are specific livelihood activities such as orchard cultivation, and livestock (mainly pigs and cows), and the proposed solutions of treating waste for this system would be highly feasible and applicable.

Converting biomass into energy products has not been fully exploited yet for farming households in rural areas, especially in the acidic soils of the Mekong Delta. Because of limited knowledge and skills by rural farmers, biofuels from agricultural waste are often not high interest. Composting and anaerobic digestion are traditional solutions for treating agricultural wastes in these areas. Biogas and compost, the secondary/immediate products after the treatment, are often returned to the system and have limited use in the household. In addition, they have low commercial value. Furthermore, biogas sludge is a potentially valuable renewable resource that is often overlooked. In other words, the various types of wastes derived from the integrated system often cause pressure on treatment solution while they could have potential to be converted into secondary energy products. Livelihood activities of a household in the acidcontaminated soils are constrained to cultivation, animal husbandry, etc. Household income is usually very low, about 100 USD per person a month on average, so it is hard to have any investment in farming activities on a larger scale.

The study was carried out on a typical farming household in acidic soil area in Tien Giang province of the Mekong Delta (latitude of $10^{\circ} 34^{\prime} 45^{\prime \prime} \mathrm{N}$, and longitude of $106^{\circ} 12^{\prime} 12^{\prime \prime} \mathrm{E}$ ). The total area of farming land within the household is 2,000 $\mathrm{m}^{2}$ which is used for two activities: raising 10 pigs in a shed and cultivating of a mixed fruit trees in an $1,000 \mathrm{~m}^{2}$ orchard. For the household livelihood, breeding of pigs brings the basic income while cultivation in the orchard also gives additional income. The biogas-tank is the only treatment facility here, which is used for treating $20 \mathrm{~kg}$ pig manure (including urine) every day. Most of the prunings of fruit trees (twigs, leaves, etc.) are left to be dried naturally, and then used as firewood for cooking.

\section{Methodology for EEE efficiency optimization for waste treatment system}


Our research proceeds to identify suitable treatment technologies for a system that generates multiple kinds of organic waste. By applying appropriate treatment solutions, such a typical LO system with diverse types of organic wastes can supply energy containing products, and due to the market value of these products, this will bring additional income for the local household as well. Composting and anaerobic digestion are the "best available" solutions to exploit all potentials for generating bioenergy products. Compost is widely appreciated for its value as organic fertilizer, whereas biofuel products such as biochar or biomass pellet are both biofuels and fertilizers, which can bring additional economic benefits for the farming purposes. Based on such a perspective, a set of potential solutions for treating different types of available wastes needs to be employed for this farming system. In addition to the traditional solutions, pyrolysis and pelleting will be added to this LO system, and they are applied to treat all kinds of biowastes in the system with purpose to produce secondary products with high energy contents like biochars and biomass pellets. However, the limitations of the living conditions of the local households somewhat affect the application of expensive waste treatment facilities.

It is hard to find the appropriate parameters and the inputs for the model/system of treatment solutions to apply them to the farming system to regional extents; therefore, the treatment solutions must fix the reference system first [36]. After simulated treatment performances, the system should be modified to support better agricultural practices on the regional scale. The specific parameters for the model/system should meet the demands of local people, for example, the unit cost of the treatment equipment and the quality of the waste resource entering the system. These values need to be optimized under the circumstances of the study area in order to find out a general model (formulas) for the best treatment practice.

The performance efficiency of treatment model/system is analyzed based on methods of material and energy flows analysis. Input and output flows participating in the treatment models contributes energy and economic benefits to economic and energy efficiency [37]. The ratio of output product and input feedstock for each treatment facility presents the energy efficiency of the treatment [38]. Economic and energy efficiencies of treatment are calculated to balance inflows and outflows, then to solve the energy loss in the system. Besides, the calculation of model efficiency considers all contained energy in the input and output for reducing energy loss and replenishing energy for the system.

The recent studies [34,39] have applied different analytical methods on economic and energy efficiency for waste treatment. Munster et al. (2015) [34] uses energy system analysis for energy efficiency and the OptiWaste tool for economic and environmental efficiency. The efficiencies are related to waste treatment, energy production versus income from recycled material or energy (i.e. heat, electricity, or biofuel). Chen (2019) et al. [33] analyzes energy systems on cost, fuel efficiency, $\mathrm{CO}_{2}$ emissions, and other parameters such as initial investment, operating cost, and turnover. Based on methods of EEE efficiency analysis from the mentioned studies, the target parameters for our proposed treatment model are related to the data of inputs (orchard prunings and pig manure) and outputs such as energy yield, profit from energy products, and environmental issues in terms of $\mathrm{CO}_{2}$ emissions. 
The efficiency of the treatment model is affected by data of the input and the output, including the energy content (namely, high heating value - $\mathrm{HHV}$ ), the potential $\mathrm{CO}_{2}$ emissions, and the profit. Three objective functions of the model are developed for optimizing the EEE efficiency of the model. They are represented by the ratio of output energy to input energy (OTI), the ratio of $\mathrm{CO}_{2}$ sequestration to $\mathrm{CO}_{2}$ emission (STE), ratio of market price to predicted price of output unit (MTP) in Table 1. Specific algorithms are applied to quantify the objective functions. They are based on two perspectives, including (1) the household concern about economic profit from the model, (2) considering the treatment system as a production function of Cobb-Douglas [40], which is described by a set of variables for technology, capital stock, labor force, energy consumption, and noise error term. Energy efficiency is based on the energy content of input and output using formula of Munster et al. (2015) [34]. Based on the formulas of Chen et al. (2019) for calculating common economic values [27], the algorithm in our study develops them to compute the profit of after-treatment products by dividing the products' market price by their estimated price. The estimated price relates to the expenditures of the treatment facility, operating cost, and the number of the expected output products. The amount of carbon in the secondary products corresponds to the carbon sequestration and is estimated by $\mathrm{CO}_{2}$ equivalent from biomass combustion [36-38]. Equation 1 is used for calculating the amount of $\mathrm{CO}_{2}$ gas based on energy in it as follows:

Carbon dioxide emission $\left(\frac{\mathrm{kg}}{\mathrm{MJ} \cdot \mathrm{yr}}\right)=\frac{\text { Biochar or pellet yield }\left(\frac{\mathrm{kg}}{\mathrm{yr}}\right) \times \text { Carbon in biochar or pellet }\left(\% \frac{\mathrm{w}}{\mathrm{w}}\right) \times \frac{44}{12}}{\text { HHV of biochar or pellet }(\mathrm{MJ})}$

Table 1 Parameters and simulation algorithm of the objective function for treatment model 


$\begin{array}{lll}\text { Parameter } & \begin{array}{l}\text { Equation } \\ \text { for objective } \\ \text { function }\end{array} & \text { Interpretation } \\ & \end{array}$

$\begin{array}{ll}\text { OTI OTI = OE/IE } & \text { OTI: Ratio of output energy to input energy or energy efficiency } \\ & \text { OE: Output energy }(\mathrm{MJ}) ; \operatorname{Amount} \text { of output product }\left(\mathrm{kg}, \mathrm{m}^{3}\right) \\ \text { times HHV of product }(\mathrm{MJ} / \mathrm{kg}) & \\ & \mathrm{IE}: \text { input energy }(\mathrm{MJ})^{\star}\end{array}$

STE STE $=\mathrm{STO} / \mathrm{ETO}$ STE: ratio of $\mathrm{CO}_{2}$ sequestration to $\mathrm{CO}_{2}$ emission

STO: ratio of the weight of sequestrated $\mathrm{CO}_{2}$ gas to the output energy $\left(\mathrm{kg} \mathrm{CO}_{2} / \mathrm{MJ}\right)$

ETO: ratio of the weight of exhausted $\mathrm{CO}_{2}$ gas to the output energy $\left(\mathrm{kg} \mathrm{CO}_{2} / \mathrm{MJ}\right)$ MTP $\quad$ MTP = MP/PP $\quad \begin{aligned} & \text { MTP: ratio of market price to predicted price of output unit of } \\ & \text { output unit }\end{aligned}$

MP: market price (\$/product unit)

PP: predicted price (\$/product unit)

$\mathrm{PP}=$ total cost for a period $(\$)$ divides number of finished output products (product units)

* Unit $(\mathrm{U})$ of both input and output biomass for OTI and STE is presented as the mass $(\mathrm{kg})$ of i.e. garden waste, pig manure, compost, biogas sludge, and the volume $\left(\mathrm{m}^{3}\right)$ of biogas, and kWh of electricity. Their energy content is expressed by HHV (joules/U); in this study, the HHV of biomass is measured, or documented by the previous literature.

A diagram of the EEE efficiency optimization framework for waste treatment solutions of a LO system is shown in Fig. 1. The multi-objective algorithm is used for the crucial parameters of the EEE efficiency and the initial input [36].

\section{Predesign of waste treatment techniques for experimental optimization}

In this study, the input feedstock for the treatment facilities are pig manure and prunings of mango trees and banana trees (common trees growing in the acidic soils in Mekong delta), and of some unpopular local fruit trees such as longan and jack fruit. The specifications of treatment need to be calibrated for the objective functions as mentioned above. The charcoal oven and the pellet machine are treatment facilities supplemental to the biogas digester (available in the current LO system), so our experiments are conducted at these facilities to Fig. out the ideal factors for objective functions. Slow pyrolysis at low temperatures below $400^{\circ} \mathrm{C}[3,4,20,22,41,42]$ is applied for this study to maximize the number of biochars (intermediate product) rather than bio-oil $[19,43]$. Our study conducts experiments of pyrolysis 
by a charcoal oven on the field while this process has been mainly found in the laboratory and demo [19]. The charcoal oven is made of materials like recycled metal, or brick, or stainless steel (Fig. 2). This oven can use dried wood, dried orchard prunnings, and biogas as fuel for combustion; and it can load $10 \mathrm{~kg}$ of biomass for each operation batch.

According to the recent literature $[3,4,20,22,25,41,42]$ and on-field experiments, three factors are found to influence the effectiveness of pyrolysis, including the moisture content of the prunings, combustion time, and combustion temperature. Pyrolysis of prunings in this LO system shows that biochar from mango prunings reached the highest energy content among that of other tree prunings. The HHV of all kinds of biochar is consistent with the studies of [42, 44]; $\mathrm{HHV}$ of biochars from dried leaves of jackfruit and mango is $16 \mathrm{MJ} / \mathrm{kg}$ and $18 \mathrm{MJ} / \mathrm{kg}$, respectively. Besides, the HHV of the biomass will increase when biomass is pelleted. Pelleting a mix of biochar with other biomass resources such as fresh manure, biogas sludge, and compost also raises its energy content. The proportion of biochar in these pellet products should account for $10 \%-40 \%$. Therefore, the mango tree prunings would recommend as feedstocks for all the treatment models to compute the predicted objective functions.

Specifications of biomass pellet are based on European and Asian standards in terms of conditions for pelleting such as pressure, particle size, moisture content, material pretreatment, and consistent equipment [5]. These standards also regulate the pellet values on size, quality, and composition. Pellet is designed as a cylindrical form with a diameter from $6 \mathrm{~mm}$ to $25 \mathrm{~mm}$, and $3 \mathrm{~mm}$ to $50 \mathrm{~mm}$ in length [20]. This research employs a civil pellet machine, that can load $100 \mathrm{~kg}$ biomass per hour, and pellet products from biomass has a diameter of $3 \mathrm{~mm}, 5 \mathrm{~mm}$, and $8 \mathrm{~mm}$, respectively with the same length of $3 \mathrm{~mm}$ (Fig. 2). Such sizes have little effect on the energy content of the pellet products.

\section{Mathematical optimization for EEE efficiency of treatment models}

Mathematical optimization is engaged in the objective functions of waste treatment models regarding EEE efficiency. A set of variables involved in the performance efficiency of the model consists of data of input and output from both biomass and the treatment facilities. Parameters of the objective and input flow are built for each treatment process, and scenario of multiple waste treatment solutions (or waste treatment model) as well. The treatment models connect current existing techniques (biogas digestion and composting) with pyrolysis and pelleting. The parameters of performance efficiency are computed by the mathematical formulas 2 and 3 . They are used to compare the models in the discussion part of this article, in which flows of input and output are analyzed separately for each treatment and the combined treatment models. The general equation describes the relationship between the efficiency $y_{a, \beta}(y:$ OTI, STE, MTP) and the input Rin (IE, PP, ETO) of the energy carrier a and the output Rout (OE, PP, STO) of the energy carrier $\beta$. There can be many energy carriers of input and output. This equation is represented as follows: 


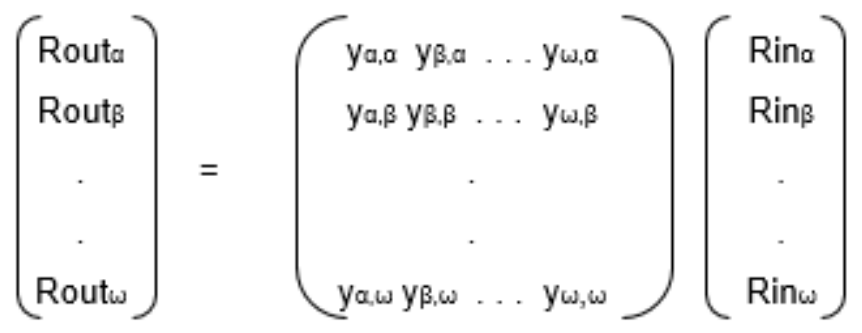

Where conditions of treatment performance optimization are $y>1$ and y reaches a maximum value.

The functional objective for product yield is the ratio of energy output to input energy or energy efficiency, wherein the number of output products and input feedstock is based on their HHV when calculating STO. The functional objective for economic benefit is to minimize total costs, in other words, to adjust treatment costs to gain market-competitive pricing for products. Treatment with a low cost for both investment and operation and the higher revenue obtained by output products proves its economic benefit. The estimated price of an output product is calculated simply by dividing the total cost for the period by the number of output products. The functional target for reducing $\mathrm{CO}_{2}$ emissions is based on the carbon content of the input and output biomass. The performance efficiency of a model (E) is the integration of objective parameters, and it is optimized by using the expression 3 as:

$$
E=\sum_{\alpha, \beta \in R \text { Rin }, \text { Rout }} O T I_{\alpha, \beta} M T P_{\alpha, \beta} S T E_{\alpha, \beta} \rightarrow \max
$$

The algorithms are applied to evaluate the EEE efficiency of the waste treatment model for a LO system. The system boundary covers on an orchard, a pig shed, and a biogas tank. Data of the treatment model are based on either actual information of the current system or calculation. The energy content and carbon content of the biomass in the treatment are shown in Table 2. Mango tree prunings and pig manure are collected every month, and are about $6 \mathrm{~kg}$ and $600 \mathrm{~kg}$, respectively. From the total quantity of collected pig manure, about $22 \mathrm{~m}^{3}$ of biogas is generated in the biogas tank within a month. The operating efficiency of biogas tank is $0.036 \mathrm{~m}^{3}$ of biogas per one kilogram of fresh manure, and fresh manure contains $90 \%$ of moisture content. The moisture content is reduced by $50 \%$ after composting. All fresh manure, biogas sludge, and compost are dried naturally in order to get the moisture content from $10 \%$ to $15 \%$ before being used for pyrolysis or pelleting. The efficiency of a charcoal oven yields $35 \%$. The energy content of biochar from orchard prunings is relatively higher than that from compost and biogas sludge, as indicated in the previous studies of $[26,27,45]$.

Table 2 Content of energy and carbon of biomass in the treatment model 


\begin{tabular}{|c|c|c|c|c|c|c|}
\hline \multirow[t]{2}{*}{ No. } & \multirow[t]{2}{*}{ Input/Output } & \multirow{2}{*}{$\begin{array}{l}\text { Short form of } \\
\text { input/output }\end{array}$} & \multirow[t]{2}{*}{ Unit } & \multirow{2}{*}{$\begin{array}{l}\mathrm{HHV} \\
\mathrm{MJ} / \text { Unit }\end{array}$} & \multirow[t]{2}{*}{ C } & \multirow[t]{2}{*}{ References } \\
\hline & & & & & & \\
\hline 1. & Prunings & $\mathrm{PR}$ & $\mathrm{kg}$ & 16.76 & 45 & [42] \\
\hline 1. & Manure slurry & MS & $\mathrm{Kg}$ & 12.52 & 37.15 & \\
\hline 1 & Biogas sludge & BS & $\mathrm{kg}$ & 13.45 & 38.55 & \\
\hline 1. & Biogas & BG & $\mathrm{m}^{3}$ & 22 & * & [46] \\
\hline 1. & $\begin{array}{l}\text { Compost from manure } \\
\text { slurry }\end{array}$ & $\mathrm{CP} \mathrm{ms}$ & $\mathrm{Kg}$ & 11.77 & 31.1 & \\
\hline 1. & Biochar from prunings & $\mathrm{BC} \mathrm{pr}$ & $\mathrm{Kg}$ & 22.79 & 59.72 & \\
\hline 1. & Biochar from biogas sludge & $\mathrm{BC}$ bs & $\mathrm{Kg}$ & 13 & 32.15 & [26] \\
\hline 1. & Biochar from manure slurry & $\mathrm{BC} \mathrm{ms}$ & $\mathrm{Kg}$ & 21.12 & 67.7 & [45] \\
\hline 1. & $\begin{array}{l}\text { Biochar from compost } \\
\text { (from manure slurry) }\end{array}$ & BC cpms & $\mathrm{Kg}$ & 14.08 & 34.79 & [27] \\
\hline 1. & Pellet from biogas sludge & PL bs & $\mathrm{Kg}$ & 14.91 & 38.4 & \\
\hline 1. & Pellet from manure slurry & PL ms & $\mathrm{Kg}$ & 13.4 & 38.01 & \\
\hline 1. & $\begin{array}{l}\text { Pellet from biochar (from } \\
\text { prunings) }\end{array}$ & PL bcpr & $\mathrm{Kg}$ & 24.9 & 69.84 & \\
\hline 1. & $\begin{array}{l}\text { Pellet from compost (from } \\
\text { manure slurry) }\end{array}$ & PL cpms & $\mathrm{Kg}$ & 12.13 & 33.75 & \\
\hline 1. & Electricity & EL & $\mathrm{kWh}$ & 3.6 & - & \\
\hline 1. & Methane gas & $\mathrm{CH}_{4}{ }^{*}$ & $\mathrm{~kg}$ & 40 & 62.5 & [47] \\
\hline
\end{tabular}

$\therefore$ Not applicable to calculate $\mathrm{CO}_{2}$ content.

*: $\mathrm{CH}_{4}$ is used to estimate the emissions of $\mathrm{CO}_{2}$ from burning biogas. Density of $\mathrm{CH}_{4}$ is $0.6 \mathrm{~kg}$ per a volume of biogas. 
The economic data of the items involving in the treatment are presented in Table 3. They are used to calculate the cost of input parameters and the profit of the output products. The waste treatment of this LO system is considered for calculation in one month; it is the time for raw biomass to be converted into compost or to decompose partly in the biogas tank. Thus, the total investment in each treatment facility is equally divided by the lifespan of the facility into the cost for a month. This study chooses the price of the secondary products with the lowest price based on the literature to investigate the potential for the treatment models to bring profit. This profit will be a good source of additional income to support the household's livelihood. The market price of biomass pellets ranges from 90 USD to 100 USD per ton, which is applied for both biofuel and fertilizer [28]. Biomass pellets are priced from 78 USD to 120 USD per ton when exported to Asian countries [7]. The international market price of biochar is 2 times higher than compost and 4 times higher than energy products for biomass digested. Besides, the system does not take labor costs into account because the labor force comes from the family members of the household, and this helps to reduce the predicted price of the output product.

Table 3 Economic value of investment (for one month) and market price of biomass

\begin{tabular}{|c|c|c|c|}
\hline No. & Item & Unit & Value \\
\hline \multicolumn{4}{|l|}{ Input } \\
\hline 1. & Biogas tank $(T)$ & VND & 83,333 \\
\hline 1. & Charcoal oven (C) & VND & 3,333 \\
\hline 1. & Pellet machine (M) & VND & 58,333 \\
\hline 1. & Compost block (B) & VND & 8,333 \\
\hline 1. & Electricity (EL) & $\mathrm{VND} / \mathrm{kWh}$ & 1,500 \\
\hline \multicolumn{4}{|c|}{ Output } \\
\hline 1. & PL & $\mathrm{VND} / \mathrm{kg}$ & 1,800 \\
\hline 1. & $\mathrm{BC}$ & $\mathrm{VND} / \mathrm{kg}$ & 1,500 \\
\hline 1. & $\mathrm{CP}$ & $\mathrm{VND} / \mathrm{kg}$ & 300 \\
\hline
\end{tabular}

$(1$ USD $=23,000$ VND $)$

\section{Results And Discussion}




\section{Scenarios of treatment model}

For selecting treatment solutions for the LO system, a large quantity of pig manure can be used as feedstock for most treatment solutions. The quantity of mango tree prunings, however, accounts for $1 \%$ of that of pig manure. Thus, the prunings are only used as feedstock for either the charcoal oven or pellet machine. The charcoal oven utilizes biogas from the biogas tank to combust the prunings into biochar; the biochar reduces more $\mathrm{CO}_{2}$ emissions than wood when used as biofuel. With $5 \mathrm{kWh}$ created by one volume of biogas [46], the biogas tank can generate about $110 \mathrm{kWh}(400 \mathrm{MJ})$ in a month, only enough to combust from $10 \mathrm{~kg}$ to $20 \mathrm{~kg}$ of mango prunings in a charcoal oven. That causes unabundant biogas to produce electricity for the system.

Due to the advantages of biofuel as mentioned above, biochars and biomass pellets can potentially support income in this LO household system. Thereby, scenarios are developed for treatment models to energy products for the existing LO system. The models show the potentials of utilizing various kinds of biowaste to generate secondary energy products. The scenarios are simulated by models (I) to (XII) and categorized by three groups (Fig. 3a, 3b, 3c), including Group 1: Pyrolysis and pelleting are prioritized for the system as presented in models (I) to (IV); Group 2: All solutions for treating both prunings and pig manure are simulated by the four models from (V) to (VIII); and Group 3: Models from (IX) to (XII) have both pelleting and either composting or anaerobic digestion, and Model (XII) has only pelleting. These proposed models have no treatment of mixing biochar from prunings with other biomass. It is because that the mass of this biochar is 20 times lower than that of other biomass, not enough for the other products.

\section{Estimation of profit for proposed model}

The local market has not discovered commercial value for biochar products, but biochar and biomass pellet have high economic value in the international market, as presented in the study of Raviv (2017) [7]. Besides, biogas is widely aware of its practical application in a small-scale farming household. Biogas production on a large scale for co-generating electricity to the regional power grid is profitable but requires a large sum of investment capital. Many commercial opportunities for biogas were evaluated by the literature of $[7,28]$, but they are not feasible for applying to a single household. Therefore, biogas is not considered for its profitability in this study, so biogas is used as combusting fuel for the charcoal oven.

Models (I) are not economically efficient when pig manure is only used for generating biogas for combusting the charcoal oven. Also, about $10 \mathrm{~kg}$ of prunings feedstock pyrolyzed to biochar would bring profits. However, to make profits from pelleting this biochar, the system needs more than $100 \mathrm{~kg}$ prunings. It leads to the fact that the models need over 50 pigs to generate sufficient biogas to combust the quantity of the prunings. Thus, scenario for treating a large volume of prunings are analyzed for the model (XIII) (Fig. 4). Because orchard prunings need to be chopped into small pieces before pelleting and composting, it takes much extra expense for the system. Thus, model (XIII) excludes composting but 
applies to pelleting biochar from prunings. Besides, this model adds the treatment of mixing biochar from prunings with other biomass. According to Hung (2017) [26], biochar from biogas sludge has lower energy content than other biochars, so the model does not include pyrolyzing biogas sludge.

In terms of profitability, models (II) to (IV) creates pellet products that achieve the profit target. For models (V) to (VIII), economic benefits from compost are higher than the pellet product. Although the amount of manure is halved for treatment solutions in models $(\mathrm{V})$ and $(\mathrm{VI})$, compost and pellet product from the manure give profits. However, only the compost products guarantee profitability in models (VII) to (VIII) when the amount of manure is equally divided for treatment solutions in these models. Models of Group 3 achieve economic benefits from pellet products, whose feedstock is pig manure and compost from pig manure. In this group, both compost and pellet products from prunings are not profitable; thus, only when the quantity of prunings is more than $100 \mathrm{~kg}$, all treatment solutions for prunings obtain economic benefits.

In terms of profitability, models (II) to (IV) creates pellet products that achieve the profit target. For models (V) to (VIII), economic benefits from compost are higher than that from the pellet product. Although the amount of manure is halved for treatment solutions in models $(\mathrm{V})$ and $(\mathrm{VI})$, compost and pellet products from this manure give profits. However, only the compost products guarantee profitability in models (VII) to (VIII) when the amount of manure is equally divided for treatment solutions in these models. Models of Group 3 achieve economic benefits from pellet products, whose feedstock is pig manure and compost from pig manure. In this group, both compost and pellet products from prunings are not profitable; thus, only when the quantity of prunings is more than $100 \mathrm{~kg}$, all treatment solutions for prunings obtain economic benefits. In general, with the same amount of pig manure feedstock for composting, anaerobic digesting, and pelleting, composting achieves the best profit.

It is concluded that two models (III) in group 1 and $(\mathrm{VI})$ in group 3 are highly profitable among models with the same pellet product from biogas sludge. Moreover, profit comes from the pellet product of pig manure by the model (III). The model (VI) has profitable products such as compost from pig manure and pellet product from this compost. Likewise, model $(X)$ without a charcoal oven still gains profits from the same products as the model $(\mathrm{VI})$.

As mentioned, a biomass pellet has a higher HHV content than that of mixing biomass with biochar. Besides, a proportion of biochar in the mixture must be above $10 \%$ to increase the HHV of the mixed product. Therefore, model (XIII) is consistent with a volume of prunings higher than $100 \mathrm{~kg}$ per month, together with $3000 \mathrm{~kg}$ manure to generate sufficient biogas for the charcoal oven. The profits come from all products by this model. Therein, profits from pyrolyzing and pelleting pig manure exceed ten times higher than the investment cost on the treatment.

\section{Energy and environment efficiency}

The energy efficiency of the treatment models is evaluated based on the energy contents of biomass. The $\mathrm{HHV}$ of pig manure and its secondary products such as biogas sludge and compost range from $11 \mathrm{MJ}$ to 
$15 \mathrm{MJ}$, in which biogas sludge has the highest HHV and compost has the lowest HHV. Biochars from these wastes have an increased HHV, except for biochar from biogas sludge [26]. The energy contents of biomass used in our study (Table 2) are lower than those found in the literature. For example, the HHV of pig manure is $19.39 \mathrm{MJ} / \mathrm{kg}$ according to Cantrell et al. [45], $16.64 \mathrm{MJ} / \mathrm{kg}$ of solid digestate in the study of [26]. Most of the HHV levels are low due to the low carbon content of feeds for pigs. In addition, compared to biochar from compost, biochar from biogas sludge has a higher energy content [27]. The biomass pellet has a higher HHV than raw biomass. Therefore, most of the models with pelleting are efficient in energy yield. It is because the pellet machine creates output products with total energy content higher than the energy of biomass feedstock, except for pelleting compost from pig manure. For pyrolyzing and composting orchard prunings, total energy efficiency on output products is lower than input feedstock. In general, models (III), (VI), (VII), and (VIII) offer higher energy efficiency than the rest models.

Based on the carbon content in biomass, all the biomass give about $0.1 \mathrm{~kg} \mathrm{CO}_{2}$ per one megajoule (MJ) of their energy. In other words, the carbon content is positively correlated with the energy content of the biomass in this study. The amount of $\mathrm{CO}_{2}$ captured in both the output product and input biomass depends on the quantities of biomass involved in the treatment. Therefore, the models (III), (VI), (VII), and (VIII) gain $\mathrm{CO}_{2}$ sequestration more than $\mathrm{CO}_{2}$ emission.

\section{Optimization of EEE efficiency}

Among models in group 3, model $(X)$ achieves all EEE efficiency from composting and pelleting pig manure. According to European standards for pellet quality in the literature of $[5,48]$, the HHV of raw biomass and compost is lower than the standardized HHV level for biofuels. The standard regulates the $\mathrm{HHV}$ level of biofuels equal to $16 \mathrm{MJ} / \mathrm{kg}$ or more. Thus, the models with a charcoal oven and pellet machine show a high energy efficiency due to their energy products as biochars and pellet products. The results of EEE efficiency analysis for the current LO system show that two models (III) and (VI) give higher overall EEE efficiency than the rest of the models. The EEE efficiency of these models is mainly based on the economic and energy value of the output products and is presented in detail in Fig. 5.

Model (XIII) is applied for a large number of orchard prunings ( $100 \mathrm{~kg})$. It leads the LO system to get about $3,000 \mathrm{~kg}$ pig manure in order to generate enough biogas for pyrolyzing prunings. It proves that all output products from this model are profitable. The model with assumed data of initial discharges makes a good profit of 8 to 20 times higher than the model with actual data. Besides, for both the hypothetical and current data, the pellet machine in this model yields energy efficiency due to the higher energy content of the output products compared with the energy content of inputs. The analytical results on economic and energy efficiency are presented in Fig. 6. Pyrolyzing is also effective in reducing $\mathrm{CO}_{2}$ emission where the amount of $\mathrm{CO}_{2}$ gas sequestrated from the output products is higher than $\mathrm{CO}_{2}$ gas exhausted. The charcoal oven, in contrast, is not efficient in both the obtained energy and $\mathrm{CO}_{2}$ reduction. In addition, mixing biochar with biogas sludge in this model is beneficial to both the energy yield and the environment. So, for the LO systems, which discharge a large amount of both orchard prunings and pig 
manure, the combination of charcoal oven and pellet machine could bring all efficiency to the economy, environment, and energy. With many benefits among the proposed models, model (XIII) is a good choice for LO systems besides models (III) and (VI). However, it is necessary to consider challenges for the system with a large number of orchard prunings. They may include restraints on economic supports and the availability of biomass residues on a regional scale [49].

Optimization of EEE efficiency for waste treatment models in a $\mathrm{LO}$ system contributes to $\mathrm{CO}_{2}$ emission reduction and production of secondary biofuels as renewable sources. Analysis of the EEE efficiency is to Fig. out the potential treatment models for this system. The ideal models like (III) and (VI) would bring additional incomes to enhance the livelihood of the local households. This work has proven economic benefits from integrating biogas tank, charcoal oven, and pellet machine in the same LO system. It shows that pelleting is effective in energy from feedstock such as fresh manure, biogas sludge, and biochar from prunings and pig manure. This treatment makes $\mathrm{CO}_{2}$ gas sequestration rather than $\mathrm{CO}_{2}$ gas exhaust. It also emphasizes the role of treatment solutions to create biofuel products. These products not only bring profitability for a small-scale farming household but also reduce environmental issues. The results indicate that it is possible to optimize EEE efficiency for agricultural waste treatment models through proper analysis and related algorithms.

\section{Conclusions}

This work presents the potential of producing biofuel from treating organic wastes of a LO farming system at the household extent. The waste treatment models are designed by supplementing treatment facilities to the LO system to optimize their EEE efficiency. The design focuses on treatment facilities creating biofuel product. The optimal model would achieve objectives related to its perfromance efficiency in terms of (i) energy yield, (ii) $\mathrm{CO}_{2}$ gas reduction, and (iii) economic benefits. The study also finds that intergating pyrolysis and pelleting maximize the EEE efficiency of the treatment models.

This study prioritizes practical applications for treatment facilities, so it provides a simulation of a set of data of inputs and outputs in treatment models for evaluating their EEE efficiency. Then, we propose an approach of multi-objective optimization by algorithms for the ideal models. Analyzing the EEE efficiency enables solving problems for waste treatment models, especially of economic and environmental issues. The treatment solutions are simple techniques, easy to handle, and free of chemicals. Therefore, similar agricultural systems can expectedly apply the results of this study. However, depending on particular conditions of the farming system, they would complete the solutions to support the livelihoods of rural people.

\section{Abbreviations}

B: Composting block; $\mathrm{BC}$ bs: Biochar from biogas sludge; $\mathrm{BC}$ cpms: Biochar from compost (from manure slurry); $B C$ ms: Biochar from manure slurry; $B C$ pr: Biochar from prunings; BC: Biochar; BG: Biogas; BS: Biogas sludge; $\mathrm{BS}$ : Biogas sludge; $\mathrm{C}$ : Charcoal oven; $\mathrm{CH}_{4}$ : Methane gas; $\mathrm{CP}$ ms: Compost from manure 
slurry; CP: Compost; EEE: Economic-environmental-energy; EL: Electricity; ETO: Ratio of the weight of exhausted $\mathrm{CO}_{2}$ gas to the output energy; HHV: High heating value; IE: Input energy; LO: Livestock-orchard; M: Pellet machine; MP: Market price; MS: Manure slurry; MS: Manure slurry; MTP: Ratio of market price to predicted price of output unit of output unit; MTP: Ratio of market price to predicted price of output unit; O: Orchard; OE: Output energy; OTI: Ratio of output energy to input energy; PL bcpr: Pellet from biochar (from prunings); PL bs: Pellet from biogas sludge; PL cpms: Pellet from compost (from manure slurry); PL ms: Pellet from manure slurry; PL: Pellet product; PP: predicted price; PR: Pruning residue; Pr: Prunings; S: Pig shed; STE: Ratio of $\mathrm{CO}_{2}$ sequestration to $\mathrm{CO}_{2}$ emission; STE: Ratio of $\mathrm{CO}_{2}$ sequestration to $\mathrm{CO}_{2}$ emission; STO: Ratio of the weight of sequestrated $\mathrm{CO}_{2}$ gas to the output energy; T: Digestion tank; $\mathrm{U}$ : Unit.

\section{Declarations}

\section{Acknowledgments}

The research is funded by the Vietnam National University - Ho Chi Minh City (VNU-HCM) under grant number NCM 2020-24-01. The authors would like to thank to the Department of Natural Resources and Environment (DONRE) in TienGiang province for assistance during site investigation and system demonstration, and the ASEAN-European Academic University network (ASEA-UNINET) for collaboration with IPPE, TU Graz, and Stadtlabor Graz, Austria, to implement this study. Special thanks to Mr. Mark Looney (Environmental Source Samplers, Inc., Wilmington, NC, mark@essknowsair.com) for your elaborative language editing on our manuscript.

\section{Authors' contributions}

NTTT initiated the research idea and developed the system under supervision of LTH, and LTH also designed and organized the whole research of this study. NTTT and SLT had a lead role in the literature review and the setup of system. NTTT, LQV, NTPT and a group of coworkers at IER were the site engineers who brought the system into application in a household farm at Tien Giang province, VN. NTPT, TTH were responsible for the communication with the other partner during the site survey and data acquisition. HS, SB and GB contributed in the research idea development, especially about the energy calculation and zero emission application for the system, and they also checked English in the final step. All authors read and approved the final manuscript.

\section{Authors' information}

Le Thanh Hai, Mr., Dr., is a full professor and Director of the Institute for Environment and Resources (IER), VNU-HCM, VN.

Nguyen Thi Thu Thao, Ms, is a PhD candidate (under supervision of Prof. LTH), and a lecturer in the Faculty of Chemical and Food Technology, University of Technology and Education, HCM City, VN. 
Nguyen Thi Phuong Thao (Ms), Tran Thi Hieu (Ms), Le Quoc Vi (Mr), are senior researchers at the Department of Environmental Management, Institute for Environment and Resources (IER), VNU-HCM, VN.

Son Le Thanh, Mr., MSc, is a lecturer at the Faculty of Environment, University of Natural Resources and Environment (HCMUNRE), Ho Chi Minh City, VN.

Hans Schnitzer, Mr., Dr., is a retired professor at the Institute for Process and Particle Engineering, Graz University of Technology, Austria.

Sibylle Braunegg, Mrs., is a senior manager in the StadtLabor Graz, a private research institution in Graz, Austria.

Gerhart Braunegg, Mr., Dr., is a retired professor at the Institute of Biotechnology and Biochemical Engineering, Graz University of Technology, Austria, and lead researcher of ARENA, a private research institution.

\section{Funding}

The research is funded by the Vietnam National University - Ho Chi Minh City (VNU-HCM) under grant number NCM 2020-24-01.

\section{Availability of data and materials}

The main datasets on which the results of the manuscript based are presented in the main paper.

\section{Ethics approval and consent to participate}

Not applicable.

\section{Consent for publication}

Not applicable.

\section{Competing interests}

The authors declare that they have no competing interests.

\section{References}

1. M. Bijarchiyan, H. Sahebi and S. Mirzamohammadi (2020) A sustainable biomass network design model for bioenergy production by anaerobic digestion technology: using agricultural residues and livestock manure. Energy, Sustainability and Society 10:10.1186/s13705-020-00252-7

2. I. Stupak, C. T. Smith and N. Clarke (2021) Governing sustainability of bioenergy, biomaterial and bioproduct supply chains from forest and agricultural landscapes. Energy, Sustainability and Society 
3. L. e. al. (2016) Pelletized carbonized biomass, methods, and apparatuses. United States Patent

4. P. J. García Nieto, E. García-Gonzalo, F. Sánchez Lasheras, J. P. Paredes-Sánchez and P. Riesgo Fernández (2019) Forecast of the higher heating value in biomass torrefaction by means of machine learning techniques. Journal of Computational and Applied Mathematics 357:284-301.

10.1016/j.cam.2019.03.009

5. K. Kang, L. Qiu, G. Sun, M. Zhu, X. Yang, Y. Yao and R. Sun (2019) Codensification technology as a critical strategy for energy recovery from biomass and other resources - A review. Renewable and Sustainable Energy Reviews 116:109414. 10.1016/j.rser.2019.109414

6. N. Dahmen, E. Henrich, E. Dinjus and F. Weirich (2012) The bioliq ${ }^{\circledR}$ bioslurry gasification process for the production of biosynfuels, organic chemicals, and energy. Energy, Sustainability and Society 2:10.1186/2192-0567-2-3

7. O. Raviv, D. Broitman, O. Ayalon and I. Kan (2018) A regional optimization model for waste-to-energy generation using agricultural vegetative residuals. Waste Manag 73:546-555.

10.1016/j.wasman.2017.10.011

8. R. Jing, Y. Li, M. Wang, B. Chachuat, J. Lin and M. Guo (2021) Coupling biogeochemical simulation and mathematical optimisation towards eco-industrial energy systems design. Applied Energy 290:116773. 10.1016/j.apenergy.2021.116773

9. J. Cortez-Arriola, J. C. J. Groot, W. A. H. Rossing, J. M. S. Scholberg, R. D. Améndola Massiotti and P. Tittonell (2016) Alternative options for sustainable intensification of smallholder dairy farms in NorthWest Michoacán, Mexico. Agricultural Systems 144:22-32. 10.1016/j.agsy.2016.02.001

10. Y. Liang, C. Wai Hui and F. You (2018) Multi-objective economic-resource-production optimization of sustainable organic mixed farming systems with nutrient recycling. Journal of Cleaner Production 196:304-330. 10.1016/j.jclepro.2018.06.040

11. R. Adelhart Toorop, V. Ceccarelli, D. Bijarniya, M. L. Jat, R. K. Jat, S. Lopez-Ridaura and J. C. J. Groot (2020) Using a positive deviance approach to inform farming systems redesign: A case study from Bihar, India. Agricultural Systems 185:102942. 10.1016/j.agsy.2020.102942

12. L. T. T. Huong, Y. Takahashi, H. Nomura, C. T. Son, T. Kusudo and M. Yabe (2020) Manure management and pollution levels of contract and non-contract livestock farming in Vietnam. Sci Total Environ 710:136200. 10.1016/j.scitotenv.2019.136200

13. R. Hosseinalizadeh, H. Izadbakhsh and H. Shakouri G (2021) A planning model for using municipal solid waste management technologies- considering Energy, Economic, and Environmental Impacts in Tehran-Iran. Sustainable Cities and Society 65:102566. 10.1016/j.scs.2020.102566 
14. L. Li, X. Li, C. Chong, C.-H. Wang and X. Wang (2020) A decision support framework for the design and operation of sustainable urban farming systems. Journal of Cleaner Production 268:121928. 10.1016/j.jclepro.2020.121928

15. J. Song, Y. Wang, S. Zhang, Y. Song, S. Xue, L. Liu, X. Lvy, X. Wang and G. Yang (2021) Coupling biochar with anaerobic digestion in a circular economy perspective: A promising way to promote sustainable energy, environment and agriculture development in China. Renewable and Sustainable Energy Reviews 144:110973. 10.1016/j.rser.2021.110973

16. X. L. Xu, H. H. Chen and Y. Li (2020) Exploring the influencing factors of continuous crop residue supply: from the perspective of a sustainable and bioenergy-oriented crop cultivation. Energy, Sustainability and Society 10:10.1186/s13705-020-00267-0

17. J. R. Bautista Angeli, A. Morales, T. LeFloc'h, A. Lakel and Y. Andres (2018) Anaerobic digestion and integration at urban scale: feedback and comparative case study. Energy, Sustainability and Society 8:10.1186/s13705-018-0170-3

18. C. Vadenbo, D. Tonini, V. Burg, T. F. Astrup, O. Thees and S. Hellweg (2018) Environmental optimization of biomass use for energy under alternative future energy scenarios for Switzerland. Biomass and Bioenergy 119:462-472. 10.1016/j.biombioe.2018.10.001

19. R. V. P. Ivona Sigurnjak, Céline Vaneeckhaute, EviMichels, and Erik Meers (2020) Biorefinery of inorganics: Recovering mineral nutrients from biomass and organic waste - manure as a resource for energy and nutrients. JohnWiley \& Sons Ltd.

20. W. Stelte, A. R. Sanadi, L. Shang, J. K. Holm, J. Ahrenfeldt and U. B. Henriksen (2012) Recent developments in biomass pelletization - A review. BioResources 7:4451-4490. 10.15376/biores.7.3.44514490

21. E. Virmond, J. D. Rocha, R. F. P. M. Moreira and H. J. José (2013) Valorization of agroindustrial solid residues and residues from biofuel production chains by thermochemical conversion: A review, citing brazil as a case study. Brazilian Journal of Chemical Engineering 30:197-229.

22. J. Iwaszko, M. Zajemska, A. Zawada, S. Szwaja and A. Poskart (2020) Vitrification of environmentally harmful by-products from biomass torrefaction process. Journal of Cleaner Production 249:119427. 10.1016/j.jclepro.2019.119427

23. E. Pehlivan, N. Ozbay, A. S. Yargic and R. Z. Sahin (2017) Production and characterization of chars from cherry pulp via pyrolysis. J Environ Manage 203:1017-1025. 10.1016/j.jenvman.2017.05.002

24. P. Pradhan, S. M. Mahajani and A. Arora (2018) Production and utilization of fuel pellets from biomass: A review. Fuel Processing Technology 181:215-232. 10.1016/j.fuproc.2018.09.021 
25. J. Ganzevles, L. Asveld and P. Osseweijer (2015) Extending bioenergy towards smart biomass use Issues of social acceptance at Park Cuijk, The Netherlands. Energy, Sustainability and Society 5:10.1186/s13705-015-0053-9

26. C. Y. Hung, W. T. Tsai, J. W. Chen, Y. Q. Lin and Y. M. Chang (2017) Characterization of biochar prepared from biogas digestate. Waste Manag 66:53-60. 10.1016/j.wasman.2017.04.034

27. J. Meng, L. Wang, X. Liu, J. Wu, P. C. Brookes and J. Xu (2013) Physicochemical properties of biochar produced from aerobically composted swine manure and its potential use as an environmental amendment. Bioresour Technol 142:641-6. 10.1016/j.biortech.2013.05.086

28. J. DiPasquale ( 2020) Opportunities and Barriers for Arizona to Supply Wood Fiber to South Korean Renewable Energy Markets. Northern Arizona University, School of Forestry

29. T. H. Le, V. T. Tran, Q. V. Le, T. P. T. Nguyen, H. Schnitzer and G. Braunegg (2016) An integrated ecosystem incorporating renewable energy leading to pollution reduction for sustainable development of craft villages in rural area: a case study at sedge mats village in Mekong Delta, Vietnam. Energy, Sustainability and Society 6:10.1186/s13705-016-0088-6

30. N. T. T. Thao, T. Van Tung, N. T. P. Thao, S. Le Thanh, S. Braunegg, G. Braunegg, H. Schnitzer and L. T. Hai (2020) Energy efficiency in an integrated agro-ecosystem within an acidic soil area of the Mekong Delta, Vietnam. Energy, Sustainability and Society 10:10.1186/s13705-020-00265-2

31. L. T. Hai, H. Schnitzer, T. van Thanh, N. T. P. Thao and G. Braunegg (2016) An integrated eco-model of agriculture and small-scale industry in craft villages toward cleaner production and sustainable development in rural areas - A case study from Mekong delta of Viet Nam. Journal of Cleaner Production 137:274-282. 10.1016/j.jclepro.2016.06.146

32. L. T. Hai, Q. B. Tran, V. T. Tra, T. P. T. Nguyen, T. N. Le, H. Schnitzer, G. Braunegg, S. Le, C. T. Hoang, X. C. Nguyen, V.-H. Nguyen, W. Peng, S. Y. Kim, S. S. Lam and Q. V. Le (2020) Integrated farming system producing zero emissions and sustainable livelihood for small-scale cattle farms: Case study in the Mekong Delta, Vietnam Environmental Pollution 265:https://doi.org/10.1016/j.envpol.2020.114853

33. G. Chen, X. Wang, J. Li, B. Yan, Y. Wang, X. Wu, R. Velichkova, Z. Cheng and W. Ma (2019) Environmental, energy, and economic analysis of integrated treatment of municipal solid waste and sewage sludge: A case study in China. Sci Total Environ 647:1433-1443. 10.1016/j.scitotenv.2018.08.104

34. M. Munster, H. Ravn, K. Hedegaard, N. Juul and M. Ljunggren Soderman (2015) Economic and environmental optimization of waste treatment. Waste Manag 38:486-95.

10.1016/j.wasman.2014.12.005

35. S. Okubo, K. Takeuchi, B. Chakranon and A. Jongskul (2003) Land characteristics and plant resources in relation to agricultural land-use planning in a humid tropical strand plain, southeastern 
Thailand. Landscape and Urban Planning 65:133-148. 10.1016/s0169-2046(03)00011-2

36. K. Tatsumi (2016) Effects of automatic multi-objective optimization of crop models on corn yield reproducibility in the U.S.A. Ecological Modelling 322:124-137. 10.1016/j.ecolmodel.2015.11.006

37. L. Kriechbaum, G. Scheiber and T. Kienberger (2018) Grid-based multi-energy systems-modelling, assessment, open source modelling frameworks and challenges. Energy, Sustainability and Society 8:10.1186/s13705-018-0176-x

38. B. Guo, X. Yang, X. Jin and Y. Zhou (2015) Eco-exergy-based ecological flow accounting of cropland ecosystem and utilisation efficiencies in China. International Journal of Exergy 17:10.1504/ijex.2015.069319

39. T. V. Tran, H. Schnitzer, G. Braunegg and H. T. Le (2017) Development of an optimization mathematical model by applying an integrated environmental indicator for selecting alternatives in cleaner production programs. Journal of Cleaner Production 154:295-308. 10.1016/j.jclepro.2017.04.009

40. B. Oryani, Y. Koo, S. Rezania and A. Shafiee (2021) Investigating the asymmetric impact of energy consumption on reshaping future energy policy and economic growth in Iran using extended CobbDouglas production function. Energy 216:119187. 10.1016/j.energy.2020.119187

41. Paolucco (2011) Apparatus for biomass torrefaction, manufacturing a storable fuel from biomass and producing offsets for the combustion products of fossl fuels. United States Patent Application Publication

42. G. Vyavahare, P. Jadhav, J. Jadhav, R. Patil, C. Aware, D. Patil, A. Gophane, Y.-H. Yang and R. Gurav (2019) Strategies for crystal violet dye sorption on biochar derived from mango leaves and evaluation of residual dye toxicity. Journal of Cleaner Production 207:296-305. 10.1016/j.jclepro.2018.09.193

43. S. Nomanbhay, B. Salman, R. Hussain and M. Y. Ong (2017) Microwave pyrolysis of lignocellulosic biomass--a contribution to power Africa. Energy, Sustainability and Society 7:10.1186/s13705-0170126-z

44. A. Gupta, S. K. Thengane and S. Mahajani (2018) CO2 gasification of char from lignocellulosic garden waste: Experimental and kinetic study. Bioresour Technol 263:180-191.

10.1016/j.biortech.2018.04.097

45. K. B. Cantrell, P. G. Hunt, M. Uchimiya, J. M. Novak and K. S. Ro (2012) Impact of pyrolysis temperature and manure source on physicochemical characteristics of biochar. Bioresour Technol 107:419-28. 10.1016/j.biortech.2011.11.084

46. G. Chinnici, R. Selvaggi, M. D'Amico and B. Pecorino (2018) Assessment of the potential energy supply and biomethane from the anaerobic digestion of agro-food feedstocks in Sicily. Renewable and Sustainable Energy Reviews 82:6-13. 10.1016/j.rser.2017.09.018 
47. S. Kalambe, R. S. Sapkal and V. S. Sapkal (2012) Low pressure separation technique of biogas low pressure separation technique of biogas into $\mathrm{CH}_{4}$ and $\mathrm{CO}_{2}$ employing pdms membrane. International Journal of Advanced Engineering Technology III:311-315.

48. A. García-Maraver, V. Popov and M. Zamorano (2011) A review of European standards for pellet quality. Renewable Energy 36:3537-3540. 10.1016/j.renene.2011.05.013

49. M. Lee, Y.-L. Lin, P.-T. Chiueh and W. Den (2020) Environmental and energy assessment of biomass residues to biochar as fuel: A brief review with recommendations for future bioenergy systems. Journal of Cleaner Production 251:119714. 10.1016/j.jclepro.2019.119714

\section{Figures}




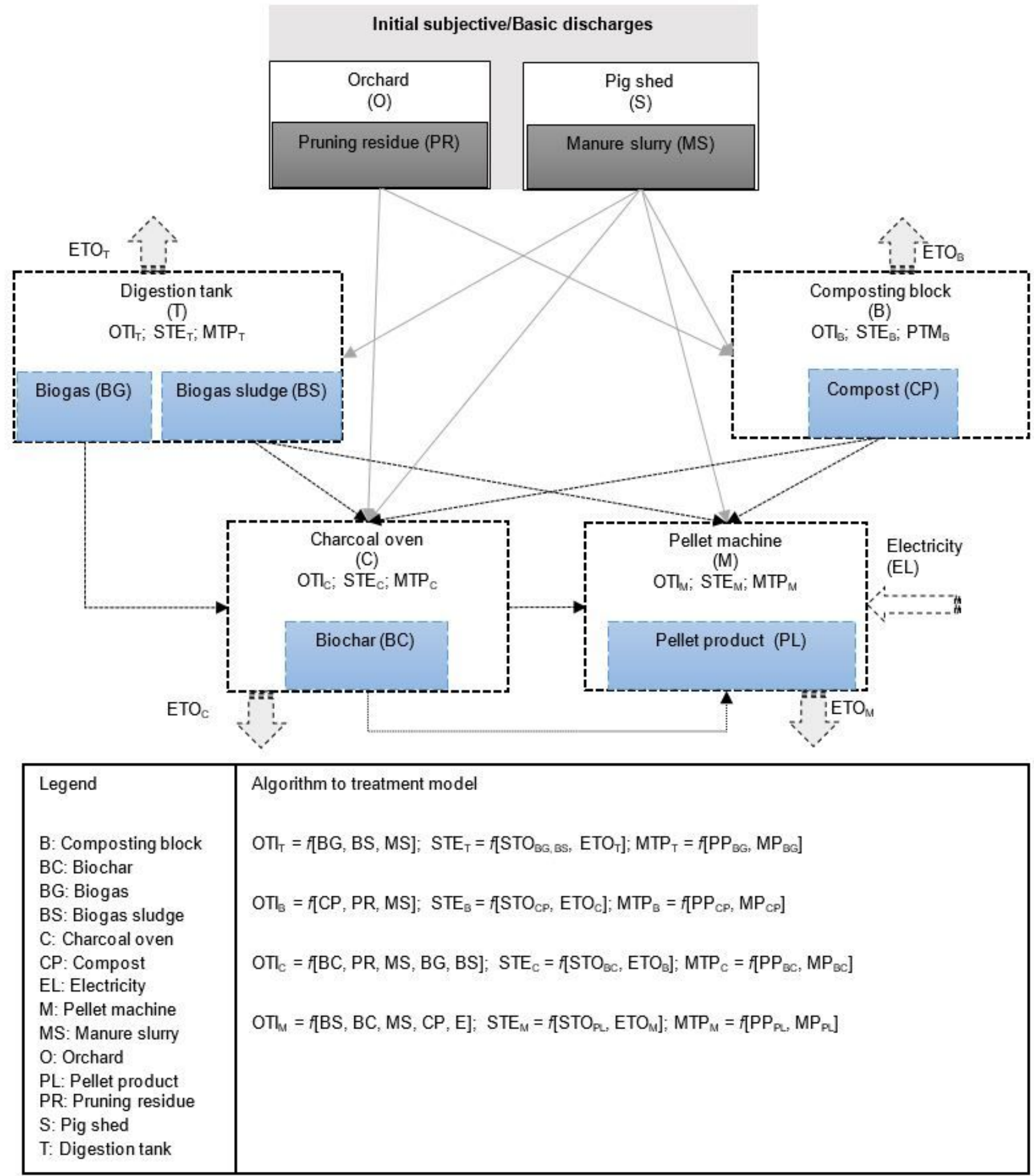

\section{Figure 1}

Diagram of EEE efficiency simulation framework of the treatment solutions and related optimization algorithms 


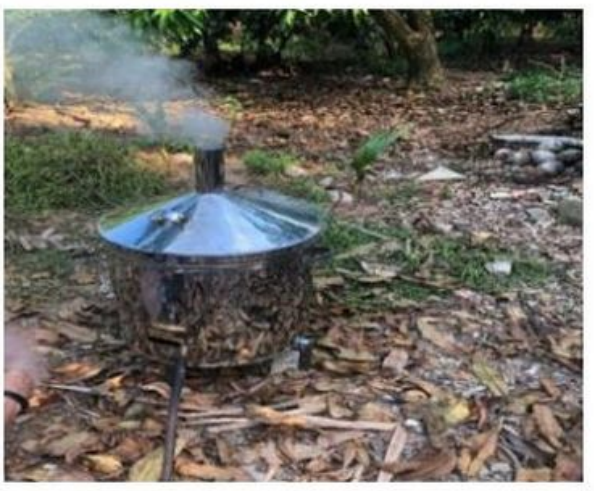

(a)
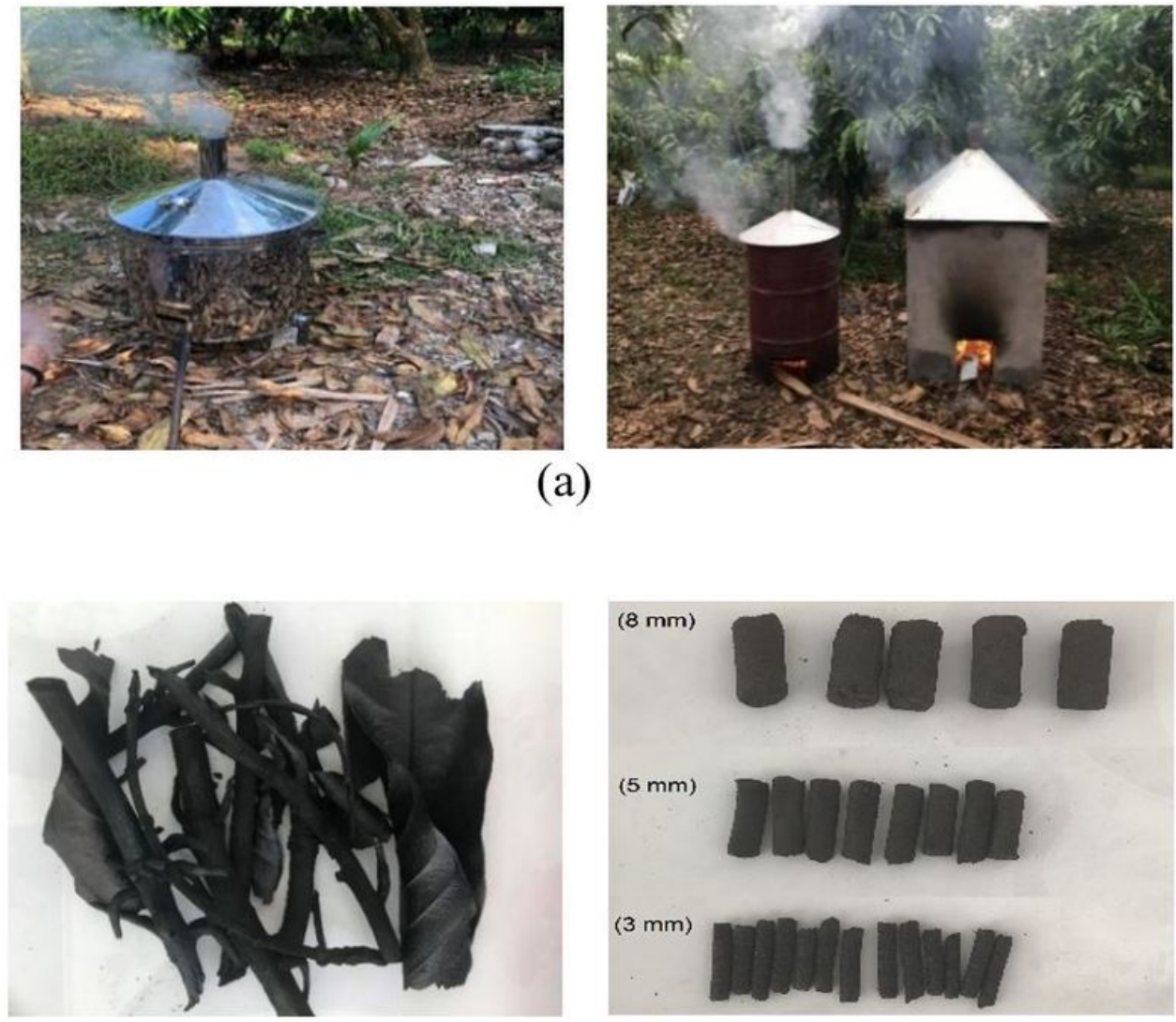

(c)

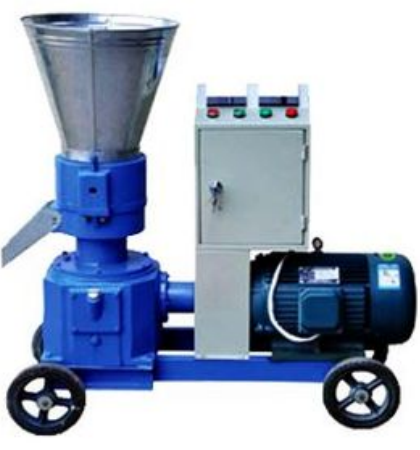

(b)

Figure 2

Charcoal oven (a) and pellet machine (b), and biochar and biomass pellet (c) 
(I)

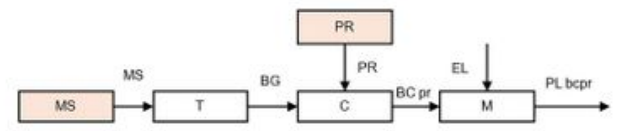

(II)

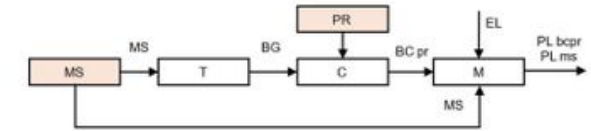

(III)

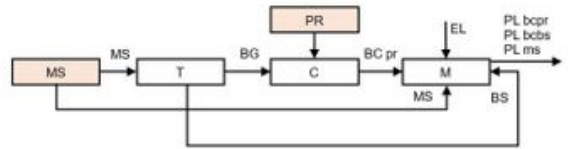

(IV)

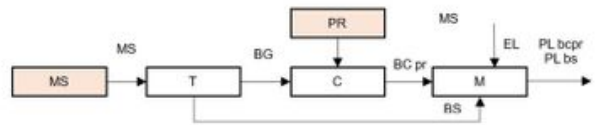

(v)

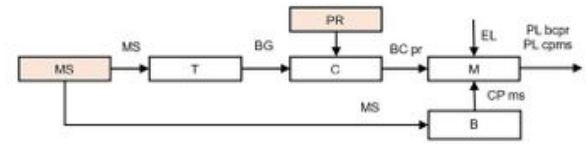

(VI)

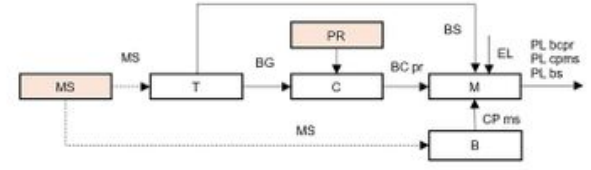

(VII)

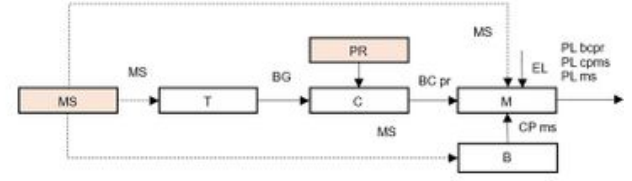

VIII)

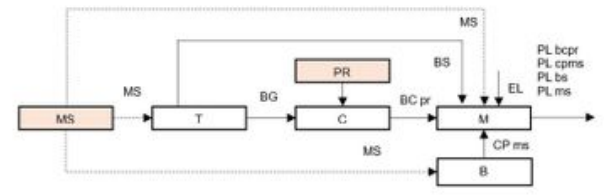

(IX)

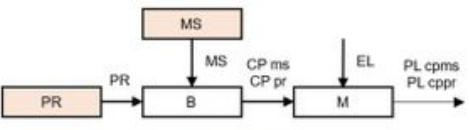

(X)

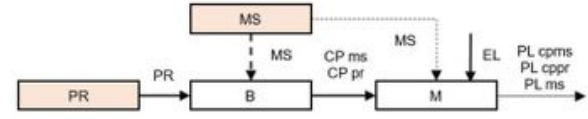

(XI)

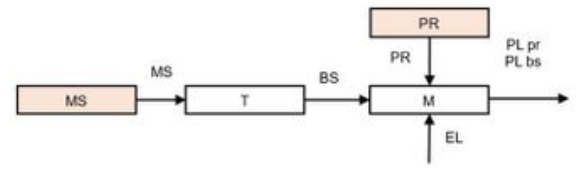

(XII)

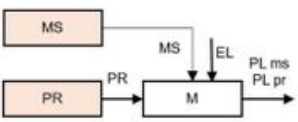

Figure 3

a Simulation of group 1 of proposed treatment models. b Simulation of group 2 of proposed treatment models. c Simulation of group 3 of proposed treatment models. 


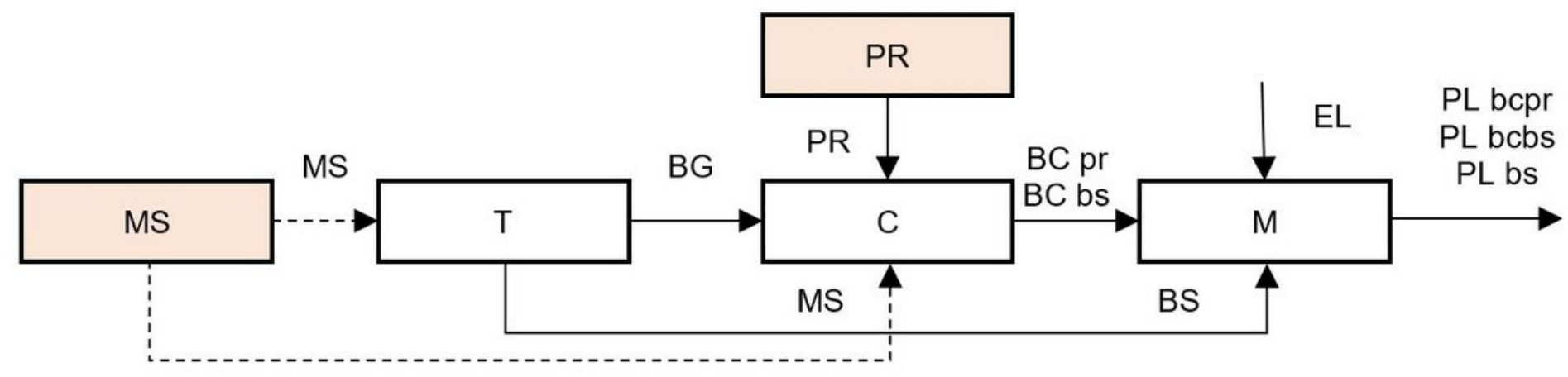

Figure 4

Simulation of treatment models with assumed data

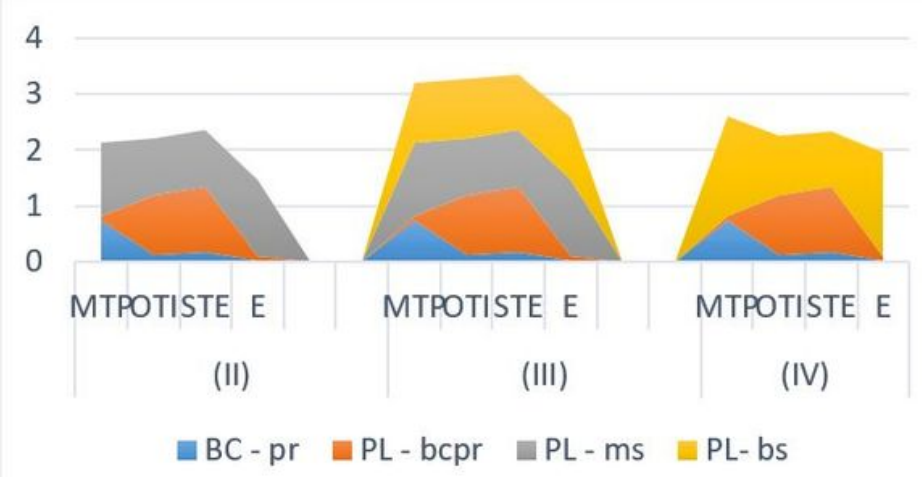

(a)

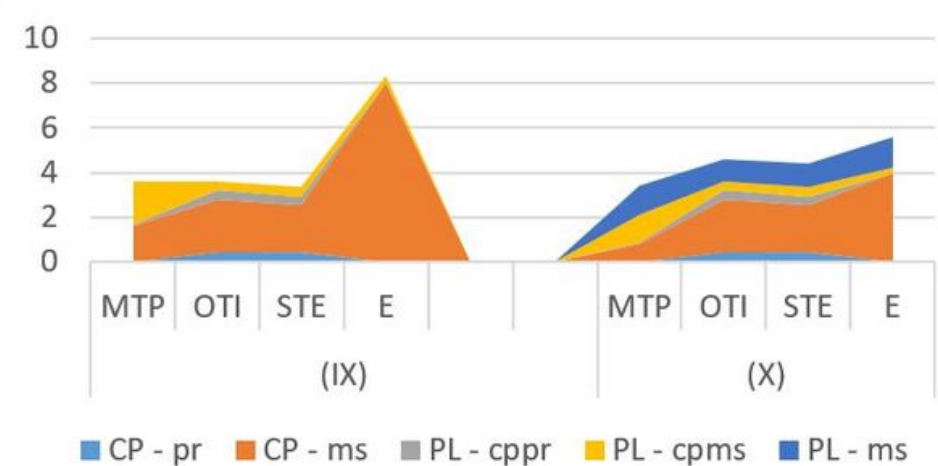

(b)

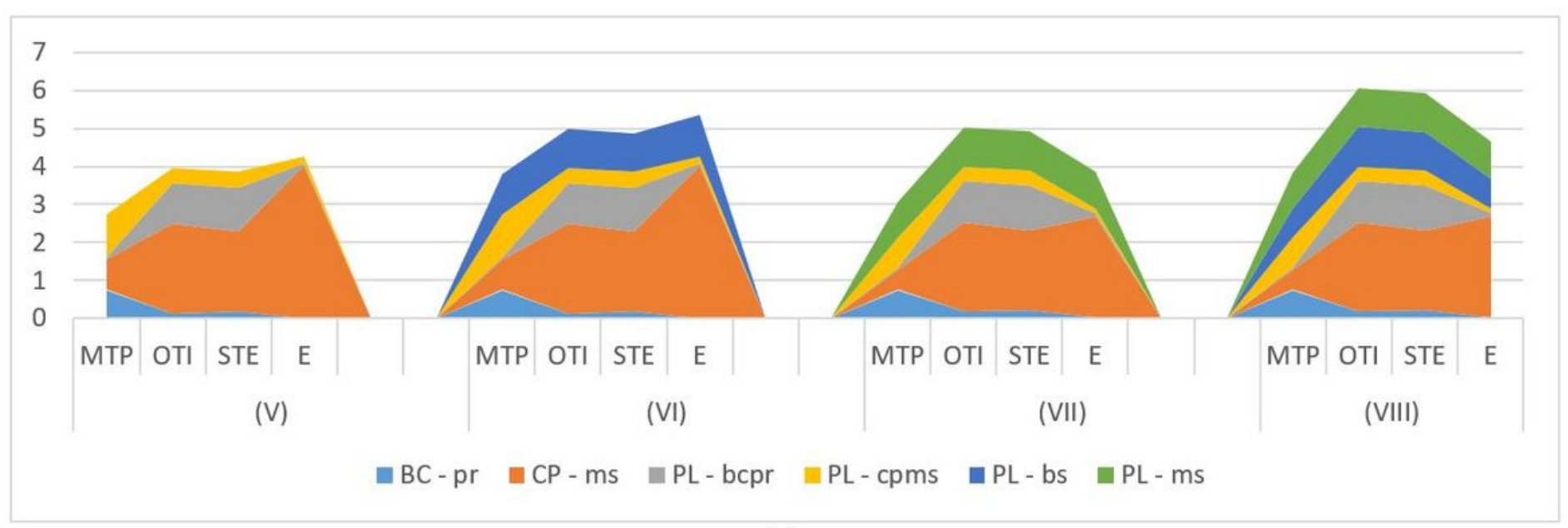

(c)

\section{Figure 5}

EEE efficiency of treatment models of (a) pyrolysis and pelleting, (b) composting and pelleting, and (c) composting, pyrolysis and pelleting 


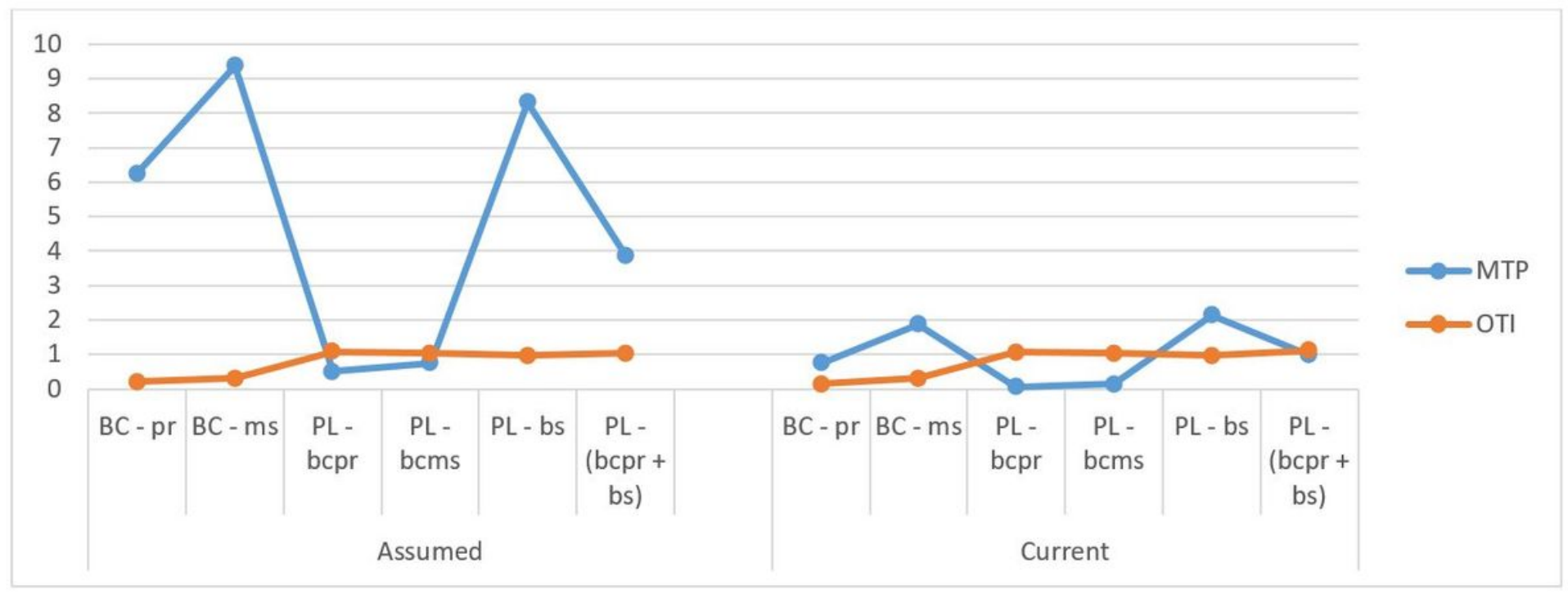

\section{Figure 6}

Economic, energy efficiency for model (XIII) with both assumed and current data 